\title{
Histopathological Changes in Adjacent Non-Tumour Mucosa in Trans Urethral Resection of Bladder Tumour Specimens of Bladder Carcinoma
}

\author{
Divya Renjini ${ }^{1}$, Muthukrishnan Chirayil Ponnappan², Vasudevan Sambu Potty ${ }^{3}$ \\ 1, 2 Department of Pathology, Government Medical College, Thiruvananthapuram, Kerala, India. \\ ${ }^{3}$ Department of Urology, Government Medical College, Thiruvananthapuram, Kerala, India.
}

\section{ABSTRACT}

\section{BACKGROUND}

Urinary bladder cancer is associated with high morbidity and mortality rates if not treated optimally. One of the causes of tumour recurrence is undiscovered residual tumour, and the existence of macroscopically invisible premalignant and malignant lesions of urothelium during the primary resection which can be detected by taking biopsy from apparently normal mucosa in the vicinity of the tumour during trans urethral resection of bladder tumour (TURBT). The primary objective was to estimate the proportion of bladder tumour showing changes in adjacent non tumour mucosa in TURBT specimens, within a period of six months. The secondary objectives were to study the association between changes in non-tumour bladder mucosa with the recurrence, seen after six months, and to study the expression of P53 in adjacent non tumour mucosa of bladder cancer.

\section{METHODS}

All cases of bladder carcinoma from trans urethral resection of bladder tumour which were sent along with adjacent non tumour mucosa and received at Department of Pathology, MCH, Trivandrum, for a period of six months were included in the study. Adjacent mucosa sent along with TURBT specimen received at our department was collected. After processing, tissue is embedded in paraffin blocks and thin sections of 4 - $5 \mu \mathrm{m}$ thickness was taken and stained with haematoxylin and eosin (H \& E). Using light microscopy, changes in adjacent mucosa were assessed for any abnormal changes and findings were correlated with collected data. P53 expression was studied in the adjacent mucosa. All details were entered in the proforma. Details collected were entered in Excel and analysed using SPSS software.

\section{RESULTS}

Out of 37 TURBT cases that were sent along with adjacent mucosa, 12 cases showed changes in adjacent mucosa accounting for $32.4 \%$. P53 positivity accounting for 18.9 $\%$, was seen in abnormal mucosa change with carcinoma in situ and dysplasia. On follow up, $8 \%$ of cases with positive biopsy finding showed recurrence.

\section{CONCLUSIONS}

Multiple biopsies from adjacent non tumour mucosa is not necessary for all patients with superficial bladder tumour. Positive findings in adjacent mucosa does not have significant correlation with tumour stage / grade, and tumour size, number of lesions or histopathological findings. Adjacent mucosa may be useful in detecting concomitant carcinoma in situ (CIS), which can be helpful in therapeutic approach.
Corresponding Author: Dr. Muthukrishnan Chirayil Ponnappan, Associate Professor, Department of Pathology, Government Medical College, Thiruvananthapuram, Kerala, India. E-mail:drmkcp@yahoo.com

DOI: $10.14260 / \mathrm{jemds} / 2021 / 207$

How to Cite This Article: Renjini D, Ponnappan MC, Potty VS. Histopathological changes in adjacent nontumour mucosa in trans urethral resection of bladder tumour specimens of bladder carcinoma. J Evolution Med Dent Sci 2021;10(13):962-967, 10.14260/jemds/2021/207

Submission 07-06-2020,

Peer Review 06-11-2020,

Acceptance 12-11-2020,

Published 29-03-2021.

Copyright (c) 2021 JEMDS. This is an open access article distributed under Creative Commons Attribution License [Attribution 4.0 International (CC BY 4.0)]

\section{KEY WORDS}

Normal Looking Mucosa, TURBT, Bladder Cancer 


\section{BACKGROUND}

Urinary bladder cancer is the seventh most common cancer. ${ }^{1}$ It is a complex disease associated with high morbidity and mortality rates if not treated optimally. Most bladder cancers are urothelial carcinomas. At presentation, roughly $75 \%$ of patients have non-muscle invasive bladder cancer and $25 \%$ have muscle-invasive or metastatic disease.

Non-invasive tumours can be divided into two categories: papillary or flat. Flat urothelium shows a wide range of atypia, from reactive to pre-neoplastic to malignant neoplasm. The latest World Health Organisation (WHO) classification of Tumours of the Urinary System and Male Genital Organs discuss about the histological finding of flat pre-neoplastic urothelial lesions: (a) urothelial hyperplasia (flat and papillary), (b) reactive urothelial atypia, (c) urothelial atypia of unknown significance (AUS), (d) urothelial dysplasia (lowgrade intraurothelial neoplasia), and (e) carcinoma in situ (high-grade intraurothelial neoplasia).2,3

Transurethral resection (TUR) is the initial diagnostic and therapeutic procedure in the management of urothelial neoplasm in the management of the urinary bladder tumours, and the quality of its performance significantly determines further course of the illness. ${ }^{4}$ In this procedure a urologist removes all macroscopically visible lesions of urothelium and gets adequate histopathological material for analysis. ${ }^{5}$

The pathologist analyses biopsy tissue specimen determines the type of tumour, and estimates the grade of malignancy and the depth of tumour infiltration in the bladder wall (stage).

Recurrence of up to $30 \%$ of solitary papillary tumours is expected during the first year after TUR, as well as up to $90 \%$ of multiple tumours with a higher-grade affecting lamina propria. $^{6}$

Various studies show that the basic causes of tumour recurrence are implantation during primary resection of a large or multiple tumours, undiscovered residual tumour, and the existence of macroscopically invisible premalignant and malignant lesions of urothelium during the primary resection. ${ }^{7,8,9}$ The existence of these lesions can be detected by taking biopsy from apparently normal mucosa in the vicinity of the tumour during TURBT.5,10

The present study aims to find out proportion of cases of adjacent mucosa showing changes in TURBT specimens of bladder carcinoma.

\section{Objectives of the Study \\ Primary Objective}

1) To estimate the proportion of bladder tumour showing changes in adjacent non tumour mucosa in TURBT specimens, within a period of six months.

\section{Secondary Objectives}

1) To find out association between changes in non-tumour bladder mucosa with the recurrence, seen after six months.

2) To find the percentage of expression of P53 in adjacent non tumour mucosa of bladder cancer.

\section{METHODS}

The present study is a longitudinal study (with follow-up) conducted from December 2016 to June 2017 in the Department of Pathology, Government Medical College, Trivandrum. TURBT specimen with adjacent mucosa specimen were obtained from Department of Urology, Government Medical College, Trivandrum.

\section{Study Variables}

- Histopathological report

- Ultrasonography (USG) report

- Demographic variables - age, sex

\section{Inclusion Criteria}

All cases of bladder carcinoma from trans urethral resection of bladder tumour which were sent along with adjacent non tumour mucosa and received at Department of Pathology, $\mathrm{MCH}$, Trivandrum, over a period of six months from the commencement of the study were included.

\section{Sample Size}

Sample size was calculated using the formula $\mathrm{n}=\frac{\mathrm{Z}_{\alpha \times \mathrm{P} \times(100-\mathrm{P})}^{2}}{\mathrm{~d}^{2}}$

$\mathrm{z}_{\alpha}=1.96$,

$\alpha=5 \%$ false positive

$\mathrm{P}=$ Anticipated $\%$ of change

$\mathrm{d}=10 \%$ (absolute precision)

$\mathrm{p}=38 \%$ [from previous studies conducted by Richterstetter et al.]

Therefore, $\mathrm{n}=\frac{1.96 \times 1.96 \times 38 \times 62}{10 \times 10}=90.5 \sim 100$

Sample size was taken as 37

\section{Exclusion Criteria}

- All cases of TURBT with no adjacent non tumour mucosa that are received at Department of Pathology.

- Specimens that doesn't have adequate tissue.

\section{Data Collection Tool}

A structured proforma was made using patient age, gender, IP number, HPR number, No. of lesion, tumour size, tumour location, tumour occurrence, histopathological diagnosis, adjacent mucosa change, type of change, stage of tumour, grade of tumour and P53 expression.

An informed written consent was obtained before the procedure. After completing the resection of the tumour, adjacent mucosa specimen was collected using cold cup biopsy from endoscopically "normal" appearing area within a perimeter of $1 \mathrm{~cm}$ from anterior, posterior, right, left and from the base of the tumour. Labelled specimen was sent along with TURBT specimen in a separate bottle with adequate amount of formalin fixative. The specimen was received in our department and after undergoing tissue processing, they were embedded in paraffin blocks and thin sections of $4-5 \mathrm{um}$ 
thickness was taken and stained with $\mathrm{H} \& \mathrm{E}$. The slides were examined under optical microscope and diagnosis was made.

The mucosa was studied, and the features looked for were adjacent mucosa "changes" whether present or absent, type of change if present-reactive atypia or hyperplasia or dysplasia or carcinoma in situ or others if any. The findings were correlated with stage and grade of tumour. The paraffin blocks of adjacent mucosa were selected and cut at $3 \mu \mathrm{m}$ thickness and immunostained with P53 and viewed under microscope and their expression in adjacent mucosa were studied in detail and documented. The histopathology slides were compared, and the neoplasms were classified and staged based on WHO classification of tumours of the urinary system and male genital organs (2016). Specimen and the data were collected for a period of six month. Based on the parameters laid in proforma, the diagnosis and adjacent mucosa were correlated. Follow-up was done for those with positive findings in the mucosa, recurrence or both.

\section{Ethical Consideration}

Ethical clearance was obtained from institutional ethics committee.

\section{Statistical Analysis}

All results and data were entered in Excel sheet and analysed by using appropriate statistical software SPSS. Percentage and P-value (statistical significance) were used for analysis.

\section{RESULTS}

During the study period a total number of 57 cases of TURBT specimens were received in our department of which 50 were male and 7 were female giving a male to female ratio of $7: 1$. Out of the total cases only 37 cases of TURBT were sent along with adjacent non tumour mucosa. Adjacent mucosal changes for each case were studied and categorised. Immunohistochemical marker P53 was studied on the adjacent mucosa.

\begin{tabular}{|ccc|}
\hline Sex & Frequency & Percent \\
Female & 5 & 13.5 \\
Male & 32 & 86.5 \\
Total & $\mathbf{3 7}$ & $\mathbf{1 0 0 . 0}$ \\
1a. Percentage & Distribution of Sample According to Sex \\
Age (in years) & Frequency & Percent \\
$<50$ & 3 & 8.1 \\
$50-59$ & 8 & 21.6 \\
$60-69$ & 13 & 35.1 \\
$70-79$ & 11 & 29.7 \\
$80-89$ & 2 & 5.4 \\
Total & $\mathbf{3 7}$ & $\mathbf{1 0 0 . 0}$ \\
1b. Percentage Distribution of Sample According to Age \\
\hline \multicolumn{3}{|c|}{ Table 1. Percentage Distribution of } \\
Sample According to Sex and Age \\
\hline \multicolumn{3}{|c}{} \\
\hline
\end{tabular}

Out of 37 cases studied for adjacent non tumour mucosa 32 were male and 5 were female giving a male to female ratio of $6.4: 1$. Age distribution of cases of TURBT specimen sent along with adjacent non tumour mucosa was found to be between 15 and 90 years of age. Majority of the cases were of the age group between $6-69$ years.

\begin{tabular}{|c|c|c|}
\hline No. of Lesions & Frequency & Percent \\
\hline Solitary & 24 & 64.9 \\
\hline Multiple & 13 & 35.1 \\
\hline Total & 37 & 100.0 \\
\hline \multicolumn{3}{|c|}{ 2a. Percentage Distribution of Cases According to Number of Lesion } \\
\hline Tumour Size & Frequency & Percent \\
\hline$<2 \mathrm{~cm}$ & 29 & 78.4 \\
\hline$>2 \mathrm{~cm}$ & 8 & 21.6 \\
\hline Total & 37 & 100.0 \\
\hline \multicolumn{3}{|c|}{ 2b. Percentage Distribution of Cases Based on the Size of Lesion } \\
\hline Tumour Location & Frequency & Percent \\
\hline Right lateral & 6 & 16.2 \\
\hline Right post lateral & 6 & 16.2 \\
\hline Left lateral & 8 & 21.6 \\
\hline Posterior & 2 & 5.4 \\
\hline Right + posterior & 2 & 5.4 \\
\hline Left posterior lateral & 1 & 2.7 \\
\hline Anterior & 1 & 2.7 \\
\hline VUJ & 1 & 2.7 \\
\hline Trigone & 1 & 2.7 \\
\hline Left + posterior & 2 & 5.4 \\
\hline Left + anterior & 1 & 2.7 \\
\hline Right posterior + left posterior & 1 & 2.7 \\
\hline Left + posterior + neck & 1 & 2.7 \\
\hline Posterior + VUJ & 1 & 2.7 \\
\hline Right + left & 1 & 2.7 \\
\hline Posterior + dome & 1 & 2.7 \\
\hline Right + neck & 1 & 2.7 \\
\hline Total & 37 & 100.0 \\
\hline \multicolumn{3}{|c|}{ 2c. Percentage Distribution of Tumour Location. } \\
\hline $\begin{array}{l}\text { Table 2. Percentage Di } \\
\text { Number of Lesions }\end{array}$ & $\begin{array}{l}\text { ution of Cas } \\
\text { and Tumor }\end{array}$ & $\begin{array}{l}\text { rding to } \\
\text { tion }\end{array}$ \\
\hline
\end{tabular}

Lesions were seen clinically by means of cystoscopy or obtained with the help of ultrasonography report. Majority of the lesion were solitary, only 12 cases were multiple. Majority of the lesions were small, of size less than $2 \mathrm{~cm}$, only 8 cases were of more than $2 \mathrm{~cm}$.

\begin{tabular}{|c|c|c|}
\hline Tumour Occurrence & Frequency & Percent \\
\hline Primary & 29 & 78.4 \\
\hline Recurrence & 8 & 21.6 \\
\hline Total & 37 & 100.0 \\
\hline \multicolumn{3}{|c|}{ 3a. Percentage Distribution of Tumour Occurrence } \\
\hline HPR Diagnosis & Frequency & Percent \\
\hline PUNLMP & 4 & 10.8 \\
\hline PUC low grade & 10 & 27.0 \\
\hline PUC high grade & 12 & 32.4 \\
\hline Invasive carcinoma & 5 & 13.5 \\
\hline Invasive carcinoma $+\mathrm{SD}$ & 1 & 2.7 \\
\hline Others & 5 & 13.5 \\
\hline Total & 37 & 100.0 \\
\hline \multicolumn{3}{|c|}{ 3b. Percentage Distribution of Histopathologically Diagnosed Lesions } \\
\hline Stage / Grade & Frequency & Percent \\
\hline PT0 & 5 & 13.5 \\
\hline PTa & 3 & 8.1 \\
\hline PTa G1 & 10 & 27.0 \\
\hline PTa G2 & 12 & 32.4 \\
\hline PT1 G1 & 1 & 2.7 \\
\hline PT2 G1 & 1 & 2.7 \\
\hline PT2 G2 & 5 & 13.5 \\
\hline Total & 37 & 100.0 \\
\hline \multicolumn{3}{|c|}{ 3c. Percentage Distribution of Stage / Grade of Tumour } \\
\hline Adjacent Change & Frequency & Percent \\
\hline Yes & 12 & 32.4 \\
\hline No & 25 & 67.6 \\
\hline Total & 37 & 100.0 \\
\hline \multicolumn{3}{|c|}{ 3d. Percentage Distribution of Cases Showing Changes in Adjacent Mucosa } \\
\hline \multicolumn{3}{|c|}{$\begin{array}{c}\text { Table 3. Percentage Distribution of Tumour Occurrence, } \\
\text { Histopathologically Diagnosed Lesion, Stage / Grade of Tumour } \\
\text { and Changes in Adjacent Mucosa }\end{array}$} \\
\hline
\end{tabular}


Most common location of the tumour included left lateral wall followed by right lateral and right postero-lateral aspect of bladder wall.

Most of the tumours in our study were primary $(78.4 \%)$ and rest were case of recurrence (21.6\%). Of the 37 cases of TURBT cases, 22 lesions were non-invasive papillary urothelial neoplasm (10-low grade, 12-high grade). Majority of the lesion belonged to pathological stage -pTaG2 followed by pTaG1. Out of 37 cases, most of the cases did not show any changes in adjacent mucosa. Only 12 cases showed changes in adjacent mucosa accounting for $32.4 \%$ of cases of total TURBT specimen sent along with adjacent mucosa.

\section{Types of Changes in Adjacent Mucosa}

Of the total cases, 15 showed normal changes, 10 cases showed cautery artefacts and 12 cases showed abnormal changes.

\begin{tabular}{|ccc|}
\hline Type of Change & Frequency & Percent \\
Normal & 15 & 40.5 \\
Cautery artefact & 10 & 27.0 \\
Reactive atypia & 3 & 8.1 \\
Hyperplasia & 1 & 2.7 \\
Dysplasia & 6 & 16.2 \\
CIS & 1 & 2.7 \\
Others & 1 & 2.7 \\
Total & $\mathbf{3 7}$ & $\mathbf{1 0 0 . 0}$ \\
\hline Table 4: Types of Changes in Adjacent Mucosa \\
\hline
\end{tabular}

\section{Abnormal Changes in Adjacent Mucosa}

Most common abnormal changes in adjacent mucosa were dysplasia (50\%).

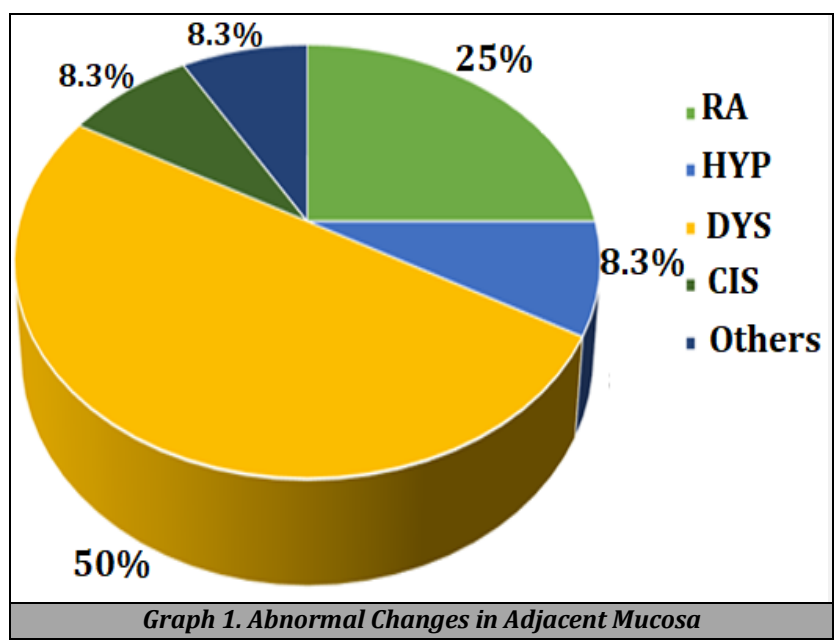

P53 Expression in Adjacent Mucosa

Of the total cases, 7 cases were positive, 30 cases were negative.

\section{DISCUSSION}

\section{Adjacent Mucosal Changes}

Out of 37 TURBT cases that were sent along with adjacent mucosa, 12 cases showed changes in adjacent mucosa accounting for $32.4 \%, 15$ showed normal changes accounting for $40.5 \%$ and 10 cases showed cautery artefacts accounting for $27 \%$.

In a study by Kaul et al. ${ }^{8}$ abnormal mucosa was found in 41 $\%$ cases where the study population was 22 cases. Richterstetter et al. ${ }^{5}$ found that $38 \%$ case showed residual lesion in the extended resected specimen of TURBT. Another study by Librenjak et al. ${ }^{6}$ showed pathological findings in $40 \%$ of biopsies in the normal appearing urothelium with a study population of 230 cases. The percentage of positive biopsy findings in other studies were between $38 \%$ and $41 \%$, and the conclusions on the basis of these results were different. In most of the studies that analysed adjacent mucosa, the site from where biopsy was taken varied from random sites to closely surrounding the resected tumour base.

Our study showed a slight decrease in proportion of case showing adjacent mucosa change. This may be due to the fact that we chose random biopsy and as there was slight increase in cases showing cautery artefacts among initially received cases, and which later rectified with cold cup biopsy for taking adjacent mucosa. Among the abnormal changes the most common was dysplasia seen in $50 \%$ of cases followed by reactive atypia accounting for $25 \%$. There was single case each of hyperplasia (8.3\%), atypia of unknown significance $(8.3 \%)$ and Carcinoma in situ (8.3\%). There was statistical significance in difference between changes in adjacent mucosa and types of changes in adjacent mucosa $(\mathrm{P}<0.001)$ In the study by Librenjak et al. the pathological findings in biopsies of the normal appearing urothelium include dysplasia $(20.6$ $\%$ ), tumour tissue (45.6\%), carcinoma in situ (33.6\%).

In the study by Matsumoto et al. ${ }^{11}$ the findings included bladder cancer (8\%), Ta tumour (3\%) and carcinoma in situ (5\%). Their study did not refer to hyperplasia, metaplasia, and dysplasia due to high level of inter-observer variation of these conditions. Abnormal findings in adjacent mucosa in the study by Kaul et al. showed carcinoma in situ (32\%) and findings corresponding to primary pathology (9\%). Richterstetter et al. did not subtype the type of change in residual lesion in the adjacent mucosa of extended TURBT. According to the literature review, concomitant Tis is a bad prognostic sign and is associated with a higher probability of progression. ${ }^{9}$ Dysplasia associated with urothelial carcinoma is also associated with greater probability of recurrence and progression. ${ }^{12}$

The most common and significant finding in all different study was carcinoma in situ, although proportion varied from $5 \%$ to $33.6 \%$ and the conclusions on the basis of these results were different in different studies.

\section{Comparison with Sex}

Of the total 57 TURBT cases that was received in our department during the study period, the male to female ratio was found to be 7:1. In our study, out of the 37 TURBT cases that were sent along with adjacent non tumour mucosa, males were predominant, accounted for $86.5 \%$ and females accounted for $13.5 \%$ of the total cases giving a male to female ratio of 6.4:1. In the study conducted by Librenjak, et al. where the study population was 230 , study period was 2 years and 9 months, the male to female ratio was found to be $3.2: 1$. Another study by Kim et al. ${ }^{13}$ where the study population was 343 and the study period was 5 years, showed that male to female ratio was 3.9:1. Both these studies show a male preponderance compared to females. On comparing the adjacent mucosa change with sex, it was found that there was 
no statistical significance in difference in findings between the two $(\mathrm{P}=0.157)$.

\section{Comparison with Age}

Age distribution of cases of TURBT specimen sent along with adjacent non tumour mucosa was found between 15 - 90 years of age, out of which the majority (35.1\%) of the patient were between 60 - 69 years of age. There were two cases with less than 20 years of age. Our results were almost similar to study by Kim et al.13 where median age group in their study population was 71 years (64 -78 years). In the study by Librenjak, et al. ${ }^{6}$ there were 176 men and 54 women, the mean age was $67 \pm 11$ years and $68 \pm 11$ years respectively. There was no statistical significance in difference between changes in adjacent mucosa with age of the patient in our study $(\mathrm{P}=$ 0.965).

\section{Comparison with Number of Lesions}

Of the total TURBT cases that were sent along with adjacent mucosa, $65 \%$ of the cases were solitary and $35 \%$ were multiple. In the study conducted by Librenjak et al. $68 \%$ of their sample had solitary lesion and $32 \%$ had multiple lesions, which is similar to our study. Richterstetter et al. studied cases where $65.6 \%$ of the lesion were unifocal and $34.4 \%$ of the lesion were multifocal. Similar results were seen in a study by Fujimoto et al. where $80 \%$ of cases were solitary and 20 cases were multiple. There is no statistical significance in difference between changes in adjacent mucosa with number of lesions of the patient $(\mathrm{P}=0.564)$

\section{Comparison with Size of Lesion}

For tumour size, two different groups were defined: tumours of $<2 \mathrm{~cm}$ and $>2 \mathrm{~cm}$. Majority of the lesion were small, of size less than $2 \mathrm{~cm}$ which accounted for $78.4 \%$, lesion more than 2 $\mathrm{cm}$ accounted for $21.6 \%$. This is slightly different from the values obtained by Librenjak et al. where small lesions $(<2$ $\mathrm{cm})$ accounted for $38 \%$ and medium $(2-5 \mathrm{~cm})$ and large $(>5$ $\mathrm{cm}$ ) lesions together accounted for $63 \%$. But almost similar to study by Matsumoto et al. and Richterstetter et al. where small lesion almost accounted for more than $60 \%$. The percentage of positive biopsy findings correlated with the tumour size in the study by Librenjak et al. and Richterstetter et al. There is no statistical significance in difference between changes in adjacent mucosa in the present study with size of lesion $(\mathrm{P}=$ 0.729). This difference in finding may be attributed to the small sample size and increased number of cases with cautery artefact.

\section{Comparison with Tumour Location}

Most common location of the tumour was left lateral followed by right lateral and right posterolateral wall of bladder. This is similar to our findings in literature review.

\section{Comparison with Tumour Occurrence}

Majority of the lesions were primary (78.4\%) with lesion discovered in the bladder for the first time, only $21.6 \%$ cases were cases of recurrence. This is almost similar to the findings in a study by Matsumoto et al. where primary case accounted for $58 \%$ of the cases and $42 \%$ case were cases of recurrence. Other studies were done mostly on adjacent mucosa of primary cases. There is no statistical significance in difference between changes in adjacent mucosa with tumour occurrence in our study ( $\mathrm{P}=0.612)$.

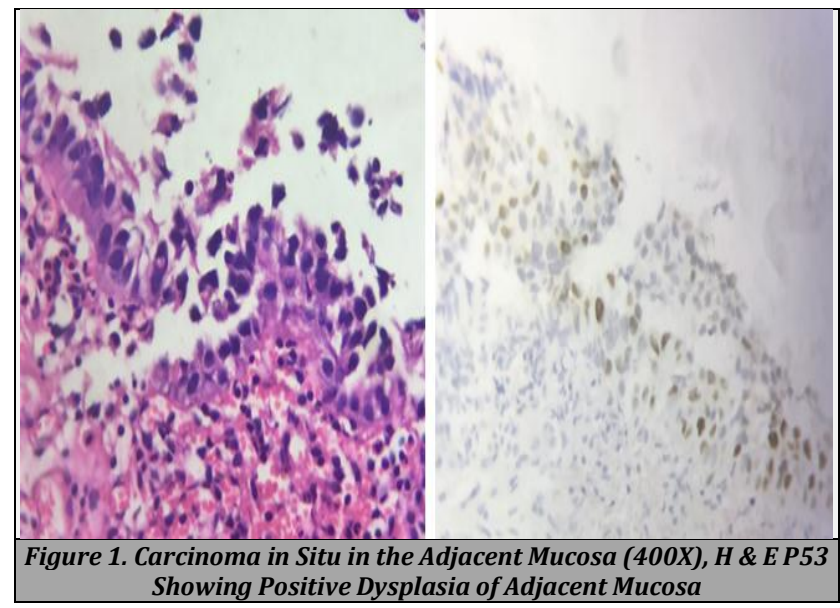

\section{Comparison with Histopathological Diagnosis of Lesion}

Of the 37 cases of TURBT cases, 22 lesions were diagnosed as non-invasive papillary urothelial neoplasm with papillary urothelial neoplasm low grade accounting for $27 \%$ and papillary urothelial neoplasm high grade accounting for the greater proportion of $32.4 \%$. "Others" accounted for $13.5 \%$ of cases and included non-neoplastic condition like polypoidal cystitis. There was no statistical significance in difference between changes in adjacent mucosa with the histopathological diagnosis of the lesion $(\mathrm{P}=0.804)$.

\section{Comparison with Stage / Grade of Tumour}

Majority lesion belonged to pathological stage pTaG2 followed by pTaG1. This is almost similar to the study by Kim et al. ${ }^{13}$ where $35.6 \%$ case belonged to Ta / Tis stage. Study by Librenjak et al. showed similar results with stage Ta accounting for $57 \%$ of the total cases. Richterstetter et al. study showed that $47.5 \%$ cases were of stage Ta. Both studies showed that positive biopsy findings were associated with higher stage / grade of tumour. But our study showed no statistical significance in difference between changes in adjacent mucosa with the stage / grade of the tumour ( $\mathrm{P}=$ 0.818).

\section{Comparison with P53 Expression in Adjacent Mucosa}

Of the total cases, 7 cases were positive accounting for $18.9 \%$. The positive cases were taken up by carcinoma in situ and all cases of dysplasia confirming our diagnosis. ${ }^{14}$ The changes in the adjacent mucosa with P53 expression were found to be statistically significant $(\mathrm{P}<0.001)$.

\section{Follow-Up}

In our study, the clinical course of disease in patients with biopsy of the normal appearing urothelium was further followed up for a period of one year. It was found that on 
performing reTURBT, $1 / 12$ (8\%) case with changes in adjacent mucosa developed similar lesion like as before and 1 / 25 (5\%) case with no positive biopsy findings in adjacent mucosa, developed similar lesion as before.

\section{CONCLUSIONS}

Taking biopsy material from the normal-appearing mucosa near the resection edge while performing TURBT is a safe procedure. Based on biopsy findings, the therapeutic approach can be changed for a small but significant number of patients. More aggressive therapy may be needed in these patients by the way of more frequent follow up or early radical cystectomy.

The proportion of bladder tumours showing changes in adjacent non tumour mucosa was $32.4 \%$. Carcinoma in situ was detected in $8.3 \%$ of cases and in such cases, multiple cold cup biopsies of the adjacent mucosa are necessary for detecting concomitant CIS as it may help in deciding the subsequent therapy. But it is not considered to be necessary for all patients with superficial bladder tumour. P53 expression in adjacent mucosa is significant and is seen with changes such as carcinoma in situ and dysplasia and thus, can be helpful in confirming the diagnosis.

On follow-up, of all the patients with positive biopsy findings in adjacent mucosa, there was recurrence rate of $8 \%$. Studies that consider routine biopsy of the normal-appearing mucosa is necessary, argue that in $6-7 \%$ of patients, based on biopsy findings, the therapeutic approach is changed. According to them, this data is significant and justifies routine biopsy of the normal-appearing mucosa. The percentage of positive findings in adjacent mucosa does not have significant correlation with tumour stage / grade, and tumour size, number of lesions or histopathological findings. Positive biopsy finding in adjacent mucosa is not an independent predictor in the recurrence and progression of the disease.

\section{Limitations of the Study}

The most important limitation of my study was the small sample size. In addition, there was bias, on patient selection and sample selection. A great proportion of my initially received sample showed cautery artefact which could be a cause of disparity in the positive findings in my study. Also, there was great amount of inter- and intra-observer variability when assessing the findings in adjacent mucosa changes.

To study the prognostic significance, clinical course of disease in patients with biopsy of the normal appearing urothelium could not be followed for a longer period of time. And within limited period only very small proportion showed recurrence.

Data sharing statement provided by the authors is available with the full text of this article at jemds.com.

Financial or other competing interests: None.

Disclosure forms provided by the authors are available with the ful text of this article at jemds.com.

\section{REFERENCES}

[1] Ferlay J, Soerjomataram I, Ervik M, et al. GLOBOCAN 2012: cancer incidence and mortality worldwide in $2012 \mathrm{v} 1.0$. International Agency for Research on Cancer 2010. http:/lglobocan.iarc fr

[2] Eble JN, Sauter G, Epstein JI, et al. World Health Organization classification of tumours: pathology and genetics of tumours of the urinary system and male genital organs. Lyon: IARC Press 2004

[3] Humphrey PA, Moch H, Cubilla AL, et al. The 2016 WHO classification of tumours of the urinary system and male genital organs-Part B: prostate and bladder tumours. Eur Urol 2016;70(1):106-19.

[4] Richards KA, Smith ND, Steinberg GD. The importance of transurethral resection of bladder tumour in the management of nonmuscle invasive bladder cancer: a systematic review of novel technologies. J Urol 2014;191(6):1655-64.

[5] Richterstetter M, Wullich B, Amann K, et al. The value of extended transurethral resection of bladder tumour (TURBT) in the treatment of bladder cancer. BJU Int 2012;110(2 Pt 2):76-9.

[6] Librenjak D, Novakovic ZS, Situm M, et al. Biopsies of the normal-appearing urothelium in primary bladder cancer. Urol Ann 2010;2(2):71-5.

[7] Hodges KB, Lopez-beltran A, Davidson DD, et al. Urothelial dysplasia and other flat lesions of the urinary bladder: clinicopathologic and molecular features. Hum Pathol 2016;41(2):155-62.

[8] Kaul A, Jacobs C, Sut M, et al. The importance of the biopsy of normal appearing bladder mucosa at the edge of primary tumour resection site. Int J Surg 2012;10(8):S99100.

[9] Cheng L, Cheville JC, Neumann RM, et al. Flat intraepithelial lesions of the urinary bladder. Cancer 2000;88(3):625-31.

[10] Cao M, Yang G, Pan J, et al. Repeated transurethral resection for non-muscle invasive bladder cancer. Int J Clin Exp Med 2015;8(1):1416-9.

[11] Fujimoto N, Harada S, Terado M, et al. Multiple biopsies of normal-looking urothelium in patients with superficial bladder cancer: are they necessary ? 2003;10(12):631-5.

[12] Smith G, Elton RA, Beynon LL, et al. Prognostic significance of biopsy results of normal-looking mucosa in cases of superficial bladder cancer. $\mathrm{Br} \mathrm{J}$ Urol 1983;55(6):665-9.

[13] Musser JE, O'Shaughnessy MJ, Kim PH, et al. Bladder biopsy of normal-appearing mucosa is not helpful in patients with unexplained positive cytology after nonmuscle invasive bladder cancer. J Urol 2015;193(1):48-52.

[14] Cheng L, Davison DD, Adams J, et al. Biomarkers in bladder cancer: translational and clinical implications. Crit Rev Oncol Hematol 2016;89(1):73-111. 